\title{
Teria o Metro-Padrão UM METro?
}

\author{
KHERIAN GRACHER
}

\begin{abstract}
Saul Kripke (1972) argued for the existence of a priori propositions that are contingently true. Kripke uses the example of a case presented by Wittgenstein (1953) about the Standard Meter of Paris. The Standard Meter is an object to determine the standard lenght, in the measure system, of a one meter unit. Wittgenstein argued that we can't affirm that the Standard Meter has one meter, since it is the standard for measure and works as a rule in the language. Therefore, the phrase "the standard meter has one meter" doesn't have a truth-value. On the other hand, Kripke argued that that phrase expresses a true proposition and can be known a priori by whom stipulated that this object will be the standard for measure. I will argue in favor a kripkean position, analyzing the dispute and thereafter answering possible objections from proponents of the wittgensteinian position.
\end{abstract}

Keywords: Contigent a priori; standard-meter; Saul Kripke; Wittgenstein.

As noções epistêmicas de se conhecer a priori ou a posteriori certas proposições são tradicionalmente comparadas com as noções metafísicas destas proposições terem necessariamente ou contingentemente seus valores de verdade. No entanto, contra essas intuições tradicionais, o filósofo americano Saul Kripke (1972) argumenta que não há qualquer relação intensional ou extensional entre esses pares de conceitos. Baseando-se em sua teoria da linguagem e em suas concepções metafísicas, Kripke defende a existência de proposições conhecíveis apenas a posteriori e que, no entanto, são necessariamente verdadeiras. O exemplo citado por Kripke de necessário a posteriori remete ao famoso exemplo de Frege acerca da estrela da manhã e estrela da tarde. Do mesmo modo, Kripke argumenta a favor da existência de proposições conhecíveis a priori cujos valores de verdade são contingentemente verdadeiras. O caso proposto por Kripke de um contingente a priori remonta a um exemplo citado por Wittgenstein (1953, §50), nomeadamente, o Metro-Padrão de Paris (i.e., um objeto que é o padrão para o sistema de medida do metro). Esse exemplo gerou uma acirrada disputa entre defensores de Wittgenstein e os defensores de Kripke. Neste artigo pretendo: apresentar como cada posição do debate compreende o caso do Metro-Padrão; fazer uma análise da disputa que não aparece na literatura atual sobre o tema; e, ao final, defender a posição kripkeana contra possíveis objeções wittgensteineanas.

Principia 19(3): 465-474 (2015).

Published by NEL — Epistemology and Logic Research Group, Federal University of Santa Catarina (UFSC), Brazil. 


\section{Wittgenstein e as Regras da Linguagem}

De acordo com Wittgenstein os jogos da linguagem dependem de certas regras que estabelecem as práticas linguísticas em uma dada comunidade. ${ }^{1}$ Tais regras gramaticais determinam o modo como podemos utilizar a linguagem, ou seja, sobre o que podemos e como devemos nos expressar através da prática linguística. Toda frase que expresse uma regra gramatical no jogo da linguagem não expressa uma proposição, i.e., não tem valor de verdade. Afirmações como "algo existe ou não-existe", "todo objeto físico é extenso" ou "o azul é colorido" são frases que apenas apresentam o modo como podemos utilizar a linguagem e sua negação seria um absurdo. Frases dessa natureza não podem ser falsas, contudo não faz sentido afirmar que elas são verdadeiras, visto que elas apenas apresentam o modo como a linguagem deve ser usada. Wittgenstein oferece uma analogia com o Metro-Padrão para compreender o uso das regras.

O Metro-Padrão é um bastão de metal que foi usado durante anos como o padrão para determinar a unidade um metro no sistema de medidas. Deste modo, ao dizermos que um objeto tem um metro de comprimento, isso significa que seu comprimento coincide com o comprimento do Metro-Padrão. No entanto, a frase "o MetroPadrão tem um metro", segundo Wittgenstein, é uma regra da linguagem. Aparentemente, o raciocínio empregado para defender esta tese é: se o Metro-Padrão não tiver um metro, então ele não poderá ser usado para definir a unidade um metro, de modo que não poderemos atribuir o comprimento métrico a nada. Basicamente, a frase "o Metro-Padrão tem um metro" não pode ser falsa, pois se o que determina o valor de comprimento um metro (o Metro-Padrão) não tiver um metro, então ele não poderá determinar o que é ter um metro de comprimento. Contudo, a frase anterior não pode ser verdadeira, uma vez que ela não afirma nada acerca do mundo, mas sim sobre o modo como devemos utilizar a linguagem. Conforme Wittgenstein diz:

(...) Há uma coisa da qual não se pode afirmar que tenha um metro de comprimento nem que não tenha um metro de comprimento, que é o MetroPadrão de Paris. - É claro que com isto não lhe atribuímos qualquer propriedade extraordinária, apenas assinalamos o papel único que desempenha no jogo de linguagem de medir com a fita métrica. (Wittgenstein 1953, §50).

Assim sendo, qualquer frase que tente predicar o comprimento em metros do Metro-Padrão não é uma frase com sentido, ela não pode ser nem verdadeira e nem falsa, uma vez que ela expressa apenas uma regra da linguagem. A intuição de Wittgenstein, aparentemente, é que o próprio Metro-Padrão não pode servir de padrão para medir a si próprio. Ou seja, uma regra em um dado jogo de linguagem não pode definir a si mesma, sendo entendida, por sua vez, apenas em seu uso no jogo. $\mathrm{O}$ argumento de Wittgenstein pode ser remontado da seguinte forma (Machado 2011):

Principia 19(3): 465-474 (2015). 
1. Algo só possui um comprimento determinado no sistema métrico se puder ser comparado com o Metro-Padrão;

2. O Metro-Padrão não pode ser comparado com o Metro-Padrão (ou seja, consigo mesmo);

3. Portanto, o metro padrão não possui um comprimento determinado no sistema métrico.

\section{Kripke e o Metro-Padrão}

Saul Kripke, em sua obra Naming and Necessity, usa do exemplo do Metro-Padrão para ilustrar o caso de uma proposição conhecível a priori e cujo valor de verdade é contingente (Kripke 1972, p.54-6). Segundo Kripke a adoção de um bastão qualquer como padrão de medida foi feita através de uma estipulação. O bastão adotado como Metro-Padrão, que chamaremos de " $S$ ", tem um comprimento $x$ no momento da estipulação (vamos chamar o momento da estipulação de " $t_{0}$ "), mas poderia não tê-lo. Deste modo, é uma verdade contingente que: $S$ tem um comprimento $x$ em $t_{0}$. O momento da estipulação nada mais é que o momento quando o termo "um metro" foi pela primeira vez introduzido na linguagem via a descrição "o comprimento de $S$ em $t_{0}$ ". O indivíduo que estipulou que $S$ seria o padrão do metro fez, basicamente, uma afirmação do tipo: Qualquer objeto terá um metro se, e somente se, tiver o comprimento de $S$ em $t_{0}$. Assim, esta descrição fixa a referência do nome "um metro". Além do mais, o nome "um metro" é um designador rígido, que será capaz de referir a todo objeto (em todo mundo possível) que tenha o mesmo comprimento de $S$ em $t_{0}$ (no mundo atual). Kripke argumenta que a frase " $S$ tem um metro em $t_{0}$ " expressa uma proposição contingente (pois $S$ poderia não ter esse comprimento em $t_{0}$ ) e também é uma proposição conhecida a priori pela pessoa que fez a estipulação (uma vez que não é uma condição necessária que o estipulador tenha qualquer experiência com o bastão $S$ para fazer a estipulação). Vale notar que, para Kripke, apenas o estipulador pode conhecer $a$ priori a estipulação, enquanto outras a conhecem apenas $a$ posteriori. $^{2}$ Podemos remontar o argumento de Kripke do seguinte modo:

a. Qualquer tem um metro se, e somente se, tem o comprimento de $S$ em $t_{0}$ (e $S$ é o Metro-Padrão).

b. $S$ tem o comprimento de $S$ em $t_{0}$.

Logo,

c. $S$ tem um metro em $t_{0}$.

A premissa (a) é a estipulação de que um metro é o comprimento de $S$ em $t_{0}$ e tal estipulação, segundo Kripke, é conhecida a priori pela pessoa que a fez. A premissa 
(b) se segue de dois princípios da lógica clássica (i.e., o princípio da reflexividade da identidade e a lei de Leibniz) ${ }^{3}$. Como (a) é uma bicondicional então podemos eliminá-la obtendo a conjunção de duas condicionais, ou seja:

a.1 Se tem um metro, então tem o comprimento de $S$ em $t_{0}$ (e $S$ é o MetroPadrão).

a.2 Se tem o comprimento de $S$ em $t_{0}$ (e $S$ é o Metro-Padrão), então tem um metro.

Através da eliminação do quantificador universal podemos trocar por $S$ e, por modus ponens de (a.2) e (b), chegamos à conclusão (c) de modo a priori, em virtude de que as premissas (a) e (b) são conhecíveis a priori (ao menos para o estipulador, argumenta Kripke) e o argumento é dedutivamente válido. ${ }^{4}$ Se Kripke estiver correto, então é possível conhecer a priori que $S$ tem um metro em $t_{0}$ (ao menos para quem estipulou que $S$ é o Metro-Padrão) e, além disso, Wittgenstein está errado quando diz que tal afirmação não faz sentido.

\section{Análise da disputa}

Não é claro na bibliografia atual onde reside a disputa sobre o caso do Metro-Padrão. Contudo, a disputa entre os defensores de Kripke e Wittgenstein parece residir na aceitação de (a.2). Um wittgensteiniano deverá rejeitar (a.2), uma vez que nem todo objeto que tenha o comprimento de $S$ terá um metro, visto que defende que o próprio objeto $S$ (o Metro-Padrão) não pode ter ou não ter um metro (visto que é ele próprio que determina o que é ter um metro). Por outro lado, um kripkeano acerca desta disputa irá defender que (a.2) faz parte da estipulação, aceitando deste modo essa premissa.

Uma razão a favor de (a.2) é que o método de medição é feito através da comparação entre o objeto que se quer medir e o Metro-Padrão. Após comparar os comprimentos, caso seja observado que ambos tenham o mesmo comprimento, então o objeto que se quer medir tem um metro. O método de raciocínio empregado na medição coaduna com (a.2), ou seja, se sabemos que um objeto tem o mesmo comprimento que o Metro-Padrão, então ele tem um metro. E parece razoável aceitarmos que o objeto que é o Metro-Padrão tem o mesmo comprimento que ele próprio (isso em virtude de uma teoria clássica da identidade).

Uma nota importante a se fazer é o uso do termo "comprimento". Há, no mínimo, dois usos diferentes desse termo. Pode-se argumentar que quando se fixa a referência do termo "um metro" no comprimento do Metro-Padrão, somos circulares em um certo nível. Isto por que quando usamos o termo "comprimento" pressupomos um sistema de medida, pois algo tem comprimento apenas se é mensurável de acordo

Principia 19(3): 465-474 (2015). 
com um sistema de medidas. Todavia, podemos usar o termo "comprimento" nos referindo a uma propriedade física dos objetos. Todo objeto extenso tem propriedades dimensionais, tais como largura, altura e profundidade. O termo "comprimento", deste modo, faz referência à uma dessas propriedades, nomeadamente, a largura de um objeto. Quando o estipulador determinou que algo tem um metro quando tem o mesmo comprimento que o Metro-Padrão, ele fixa a referência do termo "um metro" em uma propriedade física do Metro-Padrão, i.e., sua largura. Portanto, quando falamos sobre o comprimento do Metro-Padrão, nós estamos falando desta propriedade física do objeto e não de um certo valor em um sistema métrico.

Outro ponto que não é claro na bibliografia sobre o tema é uma distinção importante que deve ser feita na discussão. Há dois problemas que envolvem a disputa sobre o Metro-Padrão, um problema metafísico e outro epistêmico. O problema metafísico é se de fato $S$ tem ou não um metro. O problema epistêmico é se nos é possível saber que $S$ tem ou não um metro. Wittgenstein recusa tanto o problema metafísico, afirmando que $S$ não tem qualquer "propriedade extraordinária" que seria a propriedade de ter um metro, como recusa também o problema epistêmico, visto que, se a afirmação $S$ tem um metro não tem valor de verdade, então não podemos conhecê-la (assumindo que o conhecimento envolvido é o proposicional e que conhecimento é factivo, i.e., a proposição conhecida é verdadeira). No entanto, Kripke acredita que $S$ instancia a propriedade de ter um metro, tal como acredita que não só é possível conhecer a afirmação que $S$ tem um metro, como é possível conhecê-la a priori por quem a estipulou. Vamos tratar aqui apenas do problema metafísico, nos focando nas objeções wittgensteinianas à tese de Kripke, assim como em suas possíveis respostas.

\section{Objeções e respostas à tese de Kripke}

Uma primeira objeção que podemos abordar argumenta que tanto a pergunta "quantos metros tem o Metro-Padrão?" quanto a afirmação "o Metro-Padrão tem um metro" são logicamente impróprias e ocorrem pela má compreensão dos conceitos usados, nomeadamente, a má compreensão do que é fazer uma medição e o que é ter um metro (Pollock 2004). Se o argumento remontado de Kripke estiver correto, além da análise da disputa, podemos afirmar que não há qualquer problema lógico na conclusão que $S$ tem um metro. A estipulação feita é expressa logicamente através de uma bicondicional; a afirmação " $S$ tem o comprimento de $S$ em $t_{0}$ " se segue de um princípio da lógica clássica, a indiscernibilidade dos idênticos; e, por fim, a estrutura argumentativa é válida. Deste modo, se a análise proposta está correta, a objeção de Pollock é inócua.

De acordo com o argumento remontado de Machado (2011), uma possível objeção à tese de Kripke parte da ideia de que não podemos comparar o Metro-Padrão

Principia 19(3): 465-474 (2015). 
com o próprio Metro-Padrão (que é a premissa 2 do argumento remontado de Wittgenstein). Não fazemos comparação de um objeto consigo mesmo, mas a comparação é sempre feita entre dois ou mais objetos. O argumento, portanto, é que não compreenderíamos o conceito de comparação se dissermos que comparamos um objeto consigo mesmo.

Uma resposta a esta objeção é que a comparação é um procedimento efetivo para conhecermos uma relação entre objetos. Por exemplo, comparamos o tamanho de $S$ (o Metro-Padrão) com outro objeto qualquer, que chamaremos de " $R$ ". Através desse procedimento, se concluirmos que $S$ e $R$ têm o mesmo tamanho, então inferimos que o objeto $R$ tem um metro. Mas, como podemos notar, esse procedimento serve apenas para descobrirmos se ambos os objetos têm uma mesma propriedade, nomeadamente, o comprimento. Se ambos tiverem o mesmo comprimento (indiferente a um sistema métrico), eles compartilham de uma mesma propriedade. Quando isso ocorre nós inferimos então que $R$ (o objeto comparado) tem um metro.

Todavia, o procedimento de comparação é apenas um mecanismo para descobrirmos se ambos os objetos têm uma mesma propriedade. Se pudéssemos descobrir de outra forma (que não através de comparação) que $S$ e $R$ têm o mesmo tamanho (i.e., a mesma propriedade que designa seu comprimento), poderíamos muito bem inferir que $R$ tem um metro. Mas nós não precisamos usar de um método como a comparação para dizermos que $S$ tem o mesmo tamanho que $S$. Isso se segue de um raciocínio simples, que reside em nossas intuições do modo como a identidade se comporta. Além disso, a própria identidade é compreendida como um predicado relacional. Portanto, é irrelevante se não pudermos comparar o Metro-Padrão consigo mesmo, pois o que importa é que ele tenha a mesma propriedade de tamanho determinada na estipulação. E ele parece ter, ao menos se aceitamos a análise tradicional da identidade.

Outra objeção reside da intuição compartilhada pelos wittgensteineanos de que uma regra da linguagem não pode definir a si mesma. Como dito anteriormente, a intuição é que o próprio Metro-Padrão não pode servir de padrão para medir a si próprio, haja vista que uma regra em um dado jogo de linguagem não pode definir a si própria, sendo entendida, por sua vez, através do seu uso no jogo. No entanto, isso não parece acontecer na própria linguagem. Podemos observar, através de uma busca em qualquer livro de gramática que apresente regras de pontuação, que certas regras definem a si mesmas. Vejamos um exemplo simples sobre a regra da utilização da vírgula:

Fica entre vírgulas qualquer palavra, frase ou sentença, intercalada em uma oração. (...) Emprega-se vírgula depois da partícula não, quando ela, no princípio da oração, se refere a outra. (...) Emprega-se igualmente depois de sim, no princípio de qualquer oração. (Pontuação 2015).

Principia 19(3): 465-474 (2015). 
A regra do uso de vírgulas define a si mesma, tendo em vista que a própria regra utiliza de vírgulas para ser gramaticalmente precisa. Do mesmo modo as regras de formação de sentenças de uma linguagem natural são expressas em sentenças da própria língua. ${ }^{5}$ Portanto, não parece correto afirmarmos que uma regra não pode definir a si própria, haja vista os exemplos citados.

Outra objeção que pode ser feita à tese de Kripke é que para o padrão de medida ter algum valor prático nós não devemos fixar a referência em um comprimento que $S$ teve em $t_{0}$. Pois ao longo do tempo o bastão $S$ pode variar de comprimento e não seremos mais capazes de comparar o comprimento de $S$ em $t_{0}$ com o comprimento de qualquer outro objeto (inclusive do próprio $S$ ) em $t_{n}$ (para um $n>0$ ). Primeiramente, para fins práticos, $S$ deverá ser um material que não varie muito ao longo do tempo em condições ideais; além disso, não deveria conter na descrição que fixa a referência de "um metro" o indexical de tempo " $t_{0}$ ". Uma resposta a esta objeção é que não parece importante ao problema metafísico se somos ou não capazes de comparar o comprimento de algum objeto em $t_{n}$ em relação ao comprimento de $S$ em $t_{0}$. O problema central é se $S$ tem um metro no momento $t_{0}$ - e não a nossa incapacidade de comparação. Se for o caso que $S$ tenha um metro no momento da estipulação, então a retirada do indexical de tempo " $t_{0}$ " não alterará o fato que $S$ tem um metro em qualquer momento do tempo, ao menos enquanto ele for o Metro-Padrão.

Outra objeção é que quando queremos saber se um objeto qualquer tem um metro, nós não o comparamos a uma propriedade (cuja a natureza é tradicionalmente entendida como abstrata), mas sim ao comprimento de $S$, que é algo concreto (i.e., não-abstrato). Assim, se fixamos a referência de "um metro" em uma propriedade, então não seríamos capazes de comparar o comprimento de um objeto físico com tal propriedade, pois não parece possível compararmos algo concreto com algo abstrato. Podemos responder à essa objeção dizendo que o comprimento de um objeto é uma propriedade que ele instancia. Por exemplo, o ator Leonard Nimoy tem uma altura em 2014 e somos capazes de comparar sua altura com qualquer outra pessoa. Todavia, a altura que Nimoy tem é uma propriedade que ele instancia, nomeadamente, a propriedade de ter a altura que Leonard Nimoy tem em 2014. Quando uma propriedade que se refere a uma característica física é instanciada (como é o caso de um certo comprimento), ela tem uma contraparte na realidade. Assim, se fixamos a referência de "um metro" em uma propriedade instanciada por $S$, então o método de comparação (que é uma atividade concreta e não abstrata) é feita através da contraparte na realidade desta propriedade.

Uma última objeção é que aceitando a tese de Kripke, se a estipulação fixa a referência de "um metro" na descrição "o comprimento de $S$ em $t_{0}$ ", será metafisicamente impossível $S$ existir e não ter um metro em $t_{0}$. Pois seja lá qual for o comprimento que $S$ tiver, esse comprimento será o que determina a unidade metro, sendo então metafisicamente necessário que $S$ tenha o comprimento que tem em $t_{0}$. Do mesmo 
modo, se retirarmos o indexical de tempo da descrição que fixa a referência de "um metro", então a afirmação "S tem um metro" será necessária - e não contingente como afirma Kripke. Uma resposta a esta objeção é que há uma dupla interpretação em relação ao operador de necessidade, nomeadamente, a interpretação de re e a interpretação de dicto. Vejamos como essas interpretações funcionam:

De Dicto: Necessariamente, se um objeto $x$ tem um metro se, e somente se, $x$ tem o comprimento de $S$ (e $S$ é o Metro-Padrão), então $S$ tem um metro.

De Re: Se um objeto $x$ tem um metro se, e somente se, $x$ tem o comprimento de $S$ (e $S$ é o Metro-Padrão), então necessariamente $S$ tem um metro.

O âmbito de operação da necessidade no caso da interpretação de dicto é longo, já no caso da interpretação de re é curto. Esta diferença pode parecer inócua à objeção, mas não é. No caso da interpretação de dicto, o que se afirma é que em todo mundo possível em que $S$ é o Metro-Padrão ele tem um metro. Essa interpretação aparentemente está correta. Já no caso da interpretação de re, o que se afirma é que é necessário $S$ ter um metro, e o operador de necessidade não atua sobre a estipulação. Destarte, ao fixar a referência de "um metro" no comprimento de $S$, o comprimento que fixa a referência é o comprimento de $S$ no mundo atual. Todavia, é possível (ou há um mundo possível relativo ao atual) no qual $S$ não tem o mesmo comprimento que atualmente tem. A interpretação de re é aparentemente falsa, pois $S$ poderia não ter um metro, visto que ele poderia ter outro comprimento do que o comprimento fixado na referência (que é o comprimento que ele tem no mundo atual).

\section{Conclusão}

Ao problema metafísico devemos notar que as intuições kripkianas são melhores para responder ao problema, ao menos se aceitarmos o argumento remontado de Kripke. Um wittgensteiniano irá negar (a.2), o que permite rejeitar a conclusão de que $S$ tem um metro. No entanto, o ônus da prova fica para ele, pois ele que deverá nos convencer a rejeitar (a.2) sem que com isso tenhamos de aceitar toda a teoria de Wittgenstein. Temos de um lado o argumento remontado de Kripke (que é aparentemente cogente) e de outro lado toda a teoria wittgensteiniana, com uma conclusão que rejeita (a.2) - premissa essa que parece verdadeira. Além do mais, devemos notar que uma resposta ao problema metafísico não é uma resposta ao problema epistêmico. É argumentável que mesmo que a resposta kripkiniana ao problema metafísico esteja correta, o estipulador não seria capaz de conhecer que $S$ tem um metro de modo a priori. 


\section{Referências}

Biletzki, A.; Matar, A. 2014. Ludwig Wittgenstein. In: E. N. Zalta (ed.) The Stanford Encyclopedia of Philosophy. Disponível em:

http://plato.stanford.edu/archives/spr2014/entries/wittgenstein/

Dancy, J. 1991. Introduction to Contemporary Epistemology. New York: Wiley-Blackwell.

Machado, A. N. 2011. Measurement and the Contingent A Priori. In: C. Jäger; W. Löffler (eds.) Epistemology: Contexts, Values, Disagreement, Papers of the 34. International Wittgenstein Symposium. Austrian Ludwig Wittgenstein Society.

Grayling, A. C. 2001. Wittgenstein: A Very Short Introduction. Londres: Oxford University Press.

Kennedy, R. 1987. Salmon Versus Kripke on the A Priori. Analysis 47(3): 158-161.

Kripke, S. 1972. Naming and Necessity. New York: Wiley-Blackwell.

Malcolm, N. 1981. Kripke and the Standard Meter. Philosophical Investigations 1(4): 19-24.

Pollock, W. J. 2004. Wittgenstein on the Standard Meter. Philosophical Investigations 27(2): 148-157.

Salmon, N. 1987. How to Measure the Standard Meter. Proceedings of the Aristotelian Society 88: 193-217.

Wittgenstein, L. 1953 [1987]. Investigações Filosóficas. Tradução de Manuel Lourenço. Lisboa: Fundação Calouste Gulbenkian.

Pontuação. 2015. In: Dicionário Priberam da Língua Portuguesa. Disponível em: http://www.flip.pt/FLiP-On-line/Gramatica/Sinais-de-pontuacao

KHERIAN GRACHER

Universidade Federal de Santa Catarina

Departamento de Filosofia

Grupo de Pesquisa em Lógica e Fundamentos da Ciência

kherian@gmail.com

\section{Notas}

${ }^{1}$ Wittgenstein mudou suas perspectivas filosóficas da sua primeira obra, Tratado LógicoFilosófico, para a sua segunda obra, Investigações Filosóficas. Iremos tratar apenas o que chamam de "segundo Wittgenstein", i.e., sua abordagem filosófica das Investigações Filosóficas. Cf. Grayling (2001) e Biletzki, A.; Matar, A. (2014)

${ }^{2}$ É disputável se o estipulador pode saber a priori, no momento da estipulação, que $S$ tem um metro. Cf. Salmon 1987 e Kennedy 1987.

${ }^{3} \mathrm{O}$ princípio da reflexividade da identidade afirma que todo objeto é idêntico a si mesmo, sendo formalizado do seguinte modo: $x(x=x)$. Já a lei de Leibniz citada é o princípio da indiscernibilidade dos idênticos, i.e., se $x$ e $y$ são idênticos, então $x$ e $y$ têm as mesmas propriedades. Este princípio é formalizado em primeira-ordem como um esquema de axiomas: $x y\left(x=y \quad\left(\begin{array}{ll}x & y\end{array}\right)\right)$. E em segunda-ordem é formalizado como axioma:

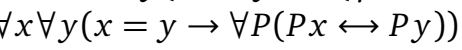

Principia 19(3): 465-474 (2015). 
${ }^{4}$ Devemos notar que o argumento utiliza o princípio de fechamento epistêmico. O estipulador sabe que (a.2) e sabe que (b), e disto infere que (c). Contudo, o princípio de fechamento epistêmico é disputável, uma vez que ele permite o argumento cético. Cf. Dancy 1991.

${ }^{5}$ Uma possível objeção é que em linguagens artificiais, como na lógica, há uma distinção entre linguagem objeto e metalinguagem. As regras de formação de fórmulas de uma linguagem artificial são expressas na metalinguagem. Mas não é isso que parece ocorrer em linguagens naturais - que Wittgenstein tem em mente.

Principia 19(3): 465-474 (2015). 